\title{
Psychiatric admissions and social deprivation: is the Jarman underprivileged area score relevant?
}

\author{
Andrew J Cotgrove, Gary Bell, Cornelius L E Katona
}

\begin{abstract}
Study objective-The aim was to assess the relationship between social deprivation, as measured by the Jarman underprivileged area score (UPA score), and psychiatric admission rates and length of stay within an inner London borough.

Design-The study was a retrospective survey of psychiatric admission rates for electoral wards in the London borough of Islington in relation to Jarman UPA scores and subscores.

Setting-Islington Health Authority psychiatric admission wards at the Whittington and Friern Hospitals

Patients-All admissions during the year of 1985 were studied $(n=778)$.

Main results-No correlation was found between the total Jarman UPA score and either admission rates or length of stay. There was, however, a correlation between the Jarman UPA subscore for ethnic minorities and admission rates $(r=0.409$, $p<0.05$ ), and between the Jarman UPA subscore for lone parents and length of stay $(\mathbf{r}=0.390, \mathrm{p}<0.05)$.

Conclusions-The Jarman UPA score at electoral ward level is not related to psychiatric morbidity, and should not therefore be used for planning local service provision.
\end{abstract}

The association between socioeconomic disadvantage and ill health is well documented. ${ }^{1}$ In terms of psychiatric morbidity, many studies have shown a high correlation with socioeconomic variables. As long ago as 1939, Faris and Dunham $^{2}$ showed that in Chicago the lowest social classes were overrepresented in areas with the largest numbers of psychiatric patients. Dohrenwend and Dohrenwend ${ }^{3}$ reported higher overall rates of psychiatric disorders among people in the lowest socioeconomic class in New York and cited 28 out of 33 studies supporting this finding. More specifically, further studies have shown correlations between socioeconomic deprivation and the use of psychiatric services. Buglass $e t \mathrm{al}^{4}$ found that several indices of social deprivation from the 1971 census data correlated with hospital admission rates for a range of psychiatric disorders. Jones et al (cited by Hirsch $^{5}$ ) found that high levels of social disadvantage in Nottingham correlated with high rates of utilisation of psychiatric services.

More recently, the Jarman underprivileged area (UPA) score ${ }^{6}$ has been used as an indicator of social deprivation and hence as a guide to health care needs and service provision. ${ }^{58}$ Jarman originally developed his score from the results of a questionnaire sent to general practitioners in England and Wales with the aim of identifying factors affecting a general practitioner's workload. Subsequent analysis revealed a number of social characteristics which were thought to increase pressure on primary care services. Jarman condensed this information to eight sociodemographic variables available from 1981 census data: elderly living alone, under fives, one parent families, unskilled, unemployed, overcrowding, moved house recently, and ethnic minorities. The scores for the eight variables were normalised, standardised, weighted according to the questionnaire result and summed to give a single global score of underprivilege for a population unit (eg, electoral ward or District Health Authority).

Hirsch ${ }^{5}$ has shown the Jarman UPA score to be a robust indicator of psychiatric bed needs across health districts. Similar correlations within a single district were found in South Hammersmith and Fulham by Foster and cited by Hirsch. ${ }^{5}$ Our aim in the present study was to extend Foster's work by correlating the individual indices of the Jarman UPA score with psychiatric admission rates and length of stay to identify other indicators of psychiatric morbidity. This information has implications for the planning and provision of local psychiatric services.

\section{Methods}

Demographic data were collected for all patients who lived in the London Borough of Islington and were admitted during the year of 1985 to psychiatric beds in the two hospitals serving Islington: Friern Hospital, which is a large psychiatric hospital taking its patients from serveral different health authorities, and the Whittington Hospital, which is a district general hospital. Patients who did not have an address in Islington were excluded from the study. In view of the strictly defined catchment areas for psychiatric admissions throughout London, this population is likely to include virtually all psychiatric admissions from the borough of Islington during 1985.

The following data were collected on all the patients included in the study: (1) hospital number; (2) address; (3) age; (4) sex; (5) date of admission; (6) date of discharge; and (7) electoral ward. The length of stay was calculated for each patient-if this was greater than one year it was recorded as 365 days.

The variables approximated to a normal distribution. Analysis was carried out using 
Student's $t$ test, Pearson's product-moment correlation coefficient, and multiple linear regression. Calculations were carried out using the Easistat Statistical Package. ${ }^{9}$

\section{Results}

Patient characteristics are listed in table I. The mean age for males was significantly younger than for females $(p<0.0001)$. Table II gives details of psychiatric admission rates, length of stay, and UPA score for each of the 20 electoral wards in the borough of Islington. No correlation was found between admission rates per 1000 population $(p=0.435)$ or mean length of stay $(p=0.115)$ and the Jarman UPA scores for the electoral wards.

Table III correlates the Jarman UPA subscores with admission rates and length of stay. Significant correlations were found between the proportion of ethnic minorities in the population

Table I Patient characteristics

\begin{tabular}{llll}
\hline & $n(\%)$ & Mean age & Mean length of stay \\
\hline Male & $387(49 \cdot 7)$ & $41 \cdot 1^{\star}$ & $53 \cdot 2$ \\
Female & $391(50 \cdot 3)$ & $46 \cdot 0$ & $58 \cdot 6$ \\
Total & $778(100)$ & $43 \cdot 6$ & 55.9
\end{tabular}

${ }^{\star} \mathrm{p}=0.0001$ and admission rates and between the proportion of lone parents and length of stay. Table IV shows the multiple correlation coefficients of the Jarman UPA subscores with admission rates and length of stay. When multiple regression analyses are applied to the data, the significance of the correlation with ethnicity is reduced to $p<0.1$ and the correlation with lone parents is no longer significant.

\section{Discussion}

The main findings of this study are in contrast to Foster's work in south Hammersmith, ${ }^{5}$ which showed a high correlation between the Jarman UPA score at electoral ward level and psychiatric admission rates. However, the range of Jarman UPA scores in south Hammersmith (12-39) is significantly greater $(p<0.01)$ than the range in the London borough Islington (22-42) (figure). Reanalysis of the admission rates for those electoral wards in South Hammersmith with Jarman UPA scores of $>22$ was performed to correspond with the range of scores in the Islington borough. No correlation was found between admission rates in the more deprived area of South Hammersmith and the Jarman UPA

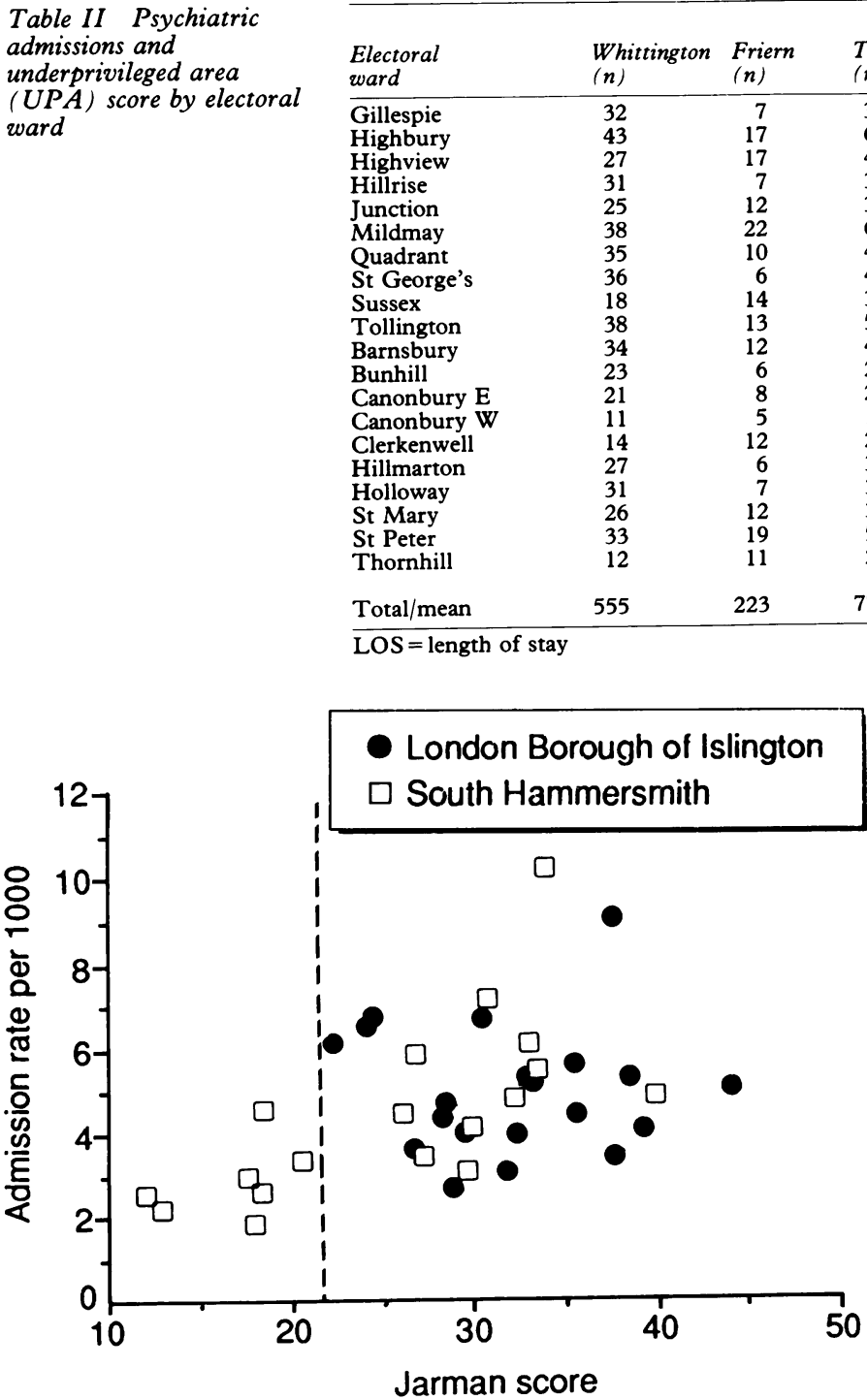

Admission rate and farman score by electoral ward scores. This suggests that the score is of limited use when applied to uniformly high levels of deprivation, as are found in the borough of Islington.

Other explanations for our findings must also be considered. The Jarman UPA score, which was designed to estimate general practitioners' workload, may not be a good indicator of the kind of social deprivation predictive of psychiatric admission rates. It omits important data such as divorce rates and homelessness and thus may overemphasise financial deprivation at the expense of social isolation. Furthermore some of the individual items may have idiosyncratic meanings at local level: for example the "moved house recently" item may be more a sign of "gentrification" in Islington than one of social deprivation. The ethnic minority statistic is based on where the head of the household comes from, irrespective of whether the rest of the household have lived all their lives in this country and are well integrated. It is also important to note that 


\begin{tabular}{|c|c|c|c|}
\hline \multirow{4}{*}{$\begin{array}{l}\text { Table III Correlation of } \\
\text { underprivileged area } \\
\text { (UPA) score and } \\
\text { subscores with admission } \\
\text { rate and length of stay }\end{array}$} & UPA variables & $\begin{array}{l}\text { Admission } \\
\text { rate }(r)\end{array}$ & $\begin{array}{l}\text { Length of } \\
\text { stay }(r)\end{array}$ \\
\hline & Total UPA score & -0.043 & $0 \cdot 214$ \\
\hline & $\begin{array}{l}\text { Elderly alone } \\
\text { Aged under } 5 \text { years } \\
\text { Lone parents } \\
\text { Unskilled } \\
\text { Unemployed } \\
\text { Overcrowded } \\
\text { Moved house } \\
\text { Ethnic minorities } \\
\end{array}$ & $\begin{array}{l}-0.253 \\
-0 \cdot 170 \\
-0.085 \\
-0.339 \\
0 \cdot 240 \\
0 \cdot 212 \\
0 \cdot 323 t \\
0 \cdot 409 \\
\end{array}$ & $\begin{array}{l}0 \cdot 073 \\
0 \cdot 328 \dagger \\
0 \cdot 390^{\star} \\
0 \cdot 182 \\
-0 \cdot 061 \\
-0 \cdot 140 \\
0 \cdot 011 \\
-0 \cdot 357 \\
\end{array}$ \\
\hline & $t p<0.1 ;{ }^{\star} p<0.05$ & & \\
\hline \multirow{2}{*}{$\begin{array}{l}\text { Table IV Multiple } \\
\text { correlation coefficients of } \\
\text { underprivileged area } \\
\text { (UPA) subscores with } \\
\text { admission rates and length } \\
\text { of stay }\end{array}$} & UPA subscores & $\begin{array}{l}\text { Admission } \\
\text { rates }(t)\end{array}$ & $\begin{array}{l}\text { Length of } \\
\text { stay }(t)\end{array}$ \\
\hline & $\begin{array}{l}\text { Elderly alone } \\
\text { Aged under } 5 \text { years } \\
\text { Lone parents } \\
\text { Unskilled } \\
\text { Unemployed } \\
\text { Overcrowded } \\
\text { Moved house } \\
\text { Ethnic minorities } \\
\end{array}$ & $\begin{array}{l}0.921 \\
1.484 \dagger\end{array}$ & $\begin{array}{l}0.424 \\
1.038\end{array}$ \\
\hline
\end{tabular}

the data used for the compilation of the Jarman score are based on the 1981 census statistics and hence were four years out of date for our sample. The population turnover in Islington has been estimated at $9 \%$ per annum, ${ }^{10}$ but may be as high as $28 \%$ in some areas (Speight $\mathrm{L}$, personal communication); thus the sociodemographic profile of the population may have changed quite significantly in this time.

The two significant correlations with Jarman subscores in our study were between ethnic minorities and admission rates, and between lone parents and length of stay. The correlation between ethnic minorities and admission rates would support the work of Harrison in Nottingham showing an increase in psychiatric morbidity among immigrants. ${ }^{11}$ It cannot, however, be concluded from our study that it is the members of the ethnic minorities themselves who had high psychiatric admission rates. The correlation between lone parents and length of stay is more difficult to interpret, but on multiple regression analysis this relationship was no longer significant.

In conclusion this study shows that the Jarman UPA score is not an appropriate planning indicator of bed needs within a health district. However, it may still have a use when applied to larger relatively stable populations with a wide range of socioeconomic variation.

Jarman UPA scores and individual census variables for Islington's 20 electoral wards were obtained from Professor Brian Jarman, and the London Borough of Islington Street Index for Electoral Wards from the Electoral Registration Officer for Islington.

1 DHSS. Report of the working group on inequalities in health (The Black Report). London: HMSO, 1980.

2 Faris REL, Dunham HW. Mental disoders in urban areas. Chicago: Hafner, 1939.

3 Dohrenwend BS, Dohrenwend BP. Socio-cultural and social-psychcological factors in the genesis of mental disorders. I Health Soc Behav 1975; 16: 365-92.

4 Buglass D, Duffy $\mathrm{K}$, Kreitman N. A register of social and medical indices by local government area in Edinburgh and Lothians. Edinburgh: Scottish Office Central Research Papers, 1980.

5 Hirsch SR. Psychiatric beds and resources: factors influencing bed use and service planning. Report of a working party of the Section for Social and Community Psychiatry of the Royal
Sertion College of Psychiatrists. London: Gaskell, 1988.

6 Jarman B. Identification of underprivileged areas. BMF Jarman B. Identificati

7 Jarman B. Validation and distribution of scores. BMF 1984; 289: 1587-92.

8 Department of Health and Social Services. Review of the resource allocation working party formula: a final report by the NHS Management Board. London: HMSO, 1988.

9 Curtis D. Easistat Version 1.08, ARC Scientific Ltd, Oxford, 1989.

10 London Research Centre. 1989/90 Round of demographic projections for the London Boroughs.

11 Harrison G, Owens D, Holton A, Neilson D, Boot D. A prospective study of severe mental disorder in AfroCaribbean patients. Psychol Med 1988; 18: 643-57. 